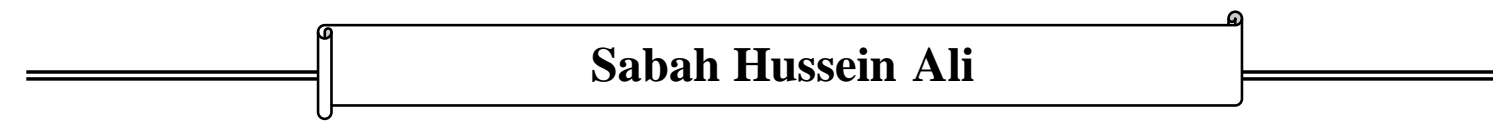

\title{
Determination of the Orthometric Height inside Mosul University campus by using GPS data and EGM96 Geoid Model
}

Sabah Hussein Ali Sensing Center Remote

University of Mosul

Received

06/03/2007
Accepted

07/06/2007

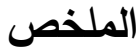

تعطي منظومة تحديد الموقع العالمي(GPS) إحداثيات ثلاثية الأبعاد (زاوية خط الطول

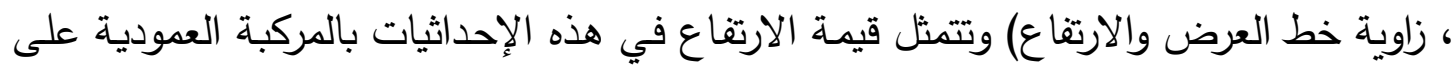

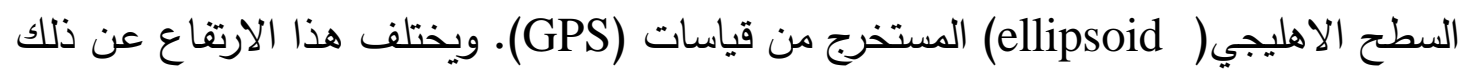
الارتفاع الدقاس في أجهزة التسوية ( Level instruments) والذي يمثل ارتفاع نقطة معينة عن سطح الجهد المتساوي والذي يسمى بالجيود (geoid) والذي يمثل تقريب لمستوى سطح البحر • ويتطلب تعيين سطح تساوي الجهد إلى كمية من المعلومات الدقيقة عن المجال ألجذبي

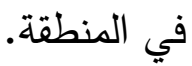

من الموديلات العالمية الحديثة التي قامت بحساب الارتفاعات الجيودية للكرة الأرضية من معطيات الأقمار الصناعية والقياسات الجذبية السطحية هو موديل الجاذبية الأرضية لسنة

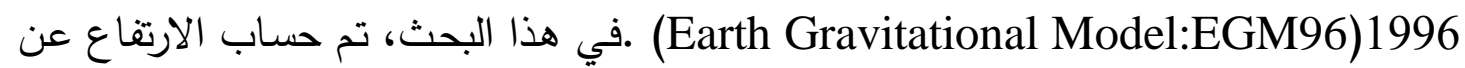

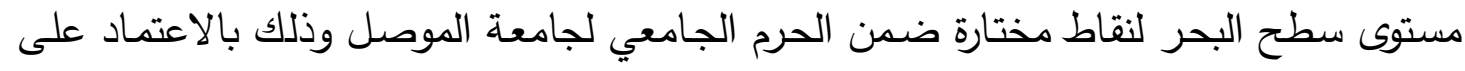
قياسات الارتفاع من منظومة (GPS) ضمن السطح الاهليجي المرجعي (WGS84 ellipsoid)

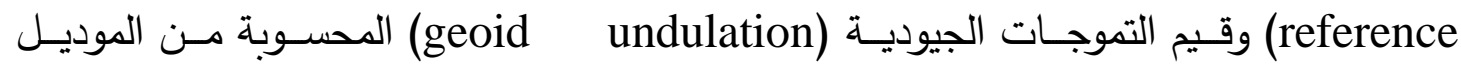
. (EGM96)

ومن خلال نتائج القياسات التي تمت في البحث، تم إعطاء قيم لرسم الخارطة الجيودية

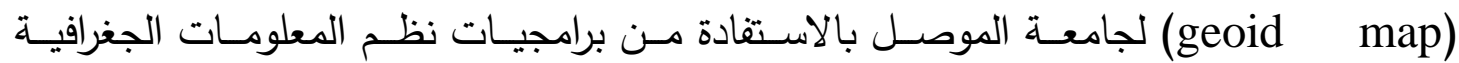

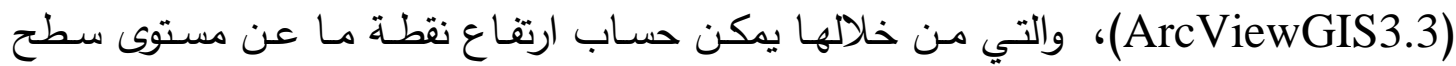
البحر من خلال قراءة الارتفاع لهذه النقطة بواسطة (GPS).

إن هذه الدراسة تعتبر محاولة أولية وضمن منطقة محدودة لرسم خارطة جيودية يمكن

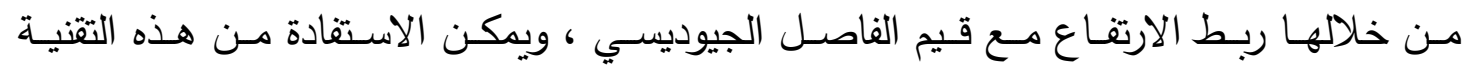

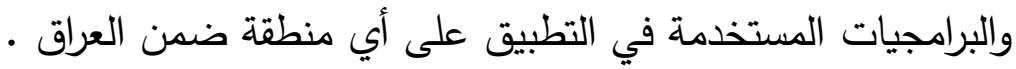




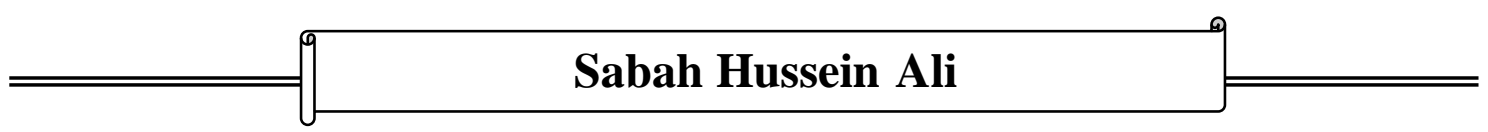

ABSTRACT

In the geodesy science, the heights determined by Global Positioning System (GPS) measurements are related to the perpendicular distance above the reference ellipsoid, while heights of Mean Sea Level (MSL) are determined with respect to geoid. The datum that defines the MSL (also called the geoid) is a complex surface that requires dense and accurate gravity data to define its shape.

Determining the geoid in Iraq is not an easy matter, mainly because of the lack of necessary data at the present time.

In the present simple study, ellipsoidal heights were derived from GPS measurements (with respect to WGS84 reference ellipsoid) at specific locations inside the campus of Mosul University. Orthometric heights (MSL) data of the test locations were then obtained according to geoid undulation (geoid height) given by the global model of the geoid (The Earth Gravitational Model 1996: EGM96). From the result of the measurements, a geoid map was produced for the study area.

This study is being considered as primary attempt, so later in the future the whole geoid separation of Iraq can be measure or part of Iraq, I hope so.

\section{Introduction}

Physical geodesy is defined as the study of the physical properties of the gravity field of the earth, the geopotential, with a view to their application in geodesy(ref.1). Almost every geodetic measurement depends in a fundamental way on the earth's gravity field. Therefore, the study of the physical properties of the gravity field and their geodetic application (which are the subject of physical geodesy) forms an essential part of the geodesist's requirements (7).

In view of this, determining the equipotential gravitational surface will still be a problem unless orthometric and geodetic heights are carefully mapped. In general, the global or large-scale features of the geoid are expressed by a spherical harmonic expression of the gravitational potential. Its higher terms are well defined by the ground gravity data, and the lower terms by the satellites tracking data (ref.2). The Earth Gravitational Model 1996 (EGM96) is one of the latest global models. This model suggests a global geoid with errors less than one meter (ref.3). It is recommended to be used with the World Geodetic System1984 (WGS84) ellipsoid.

However, the height determined by Global Positioning System: GPS measurements relates to the reference ellipsoid, while the height of (MSL) determined with respect to geoid. The geoid can be as the equipotential surface of the earth gravity field that most closely approximation the mean sea level surface (ref.4). At every point the geoid 


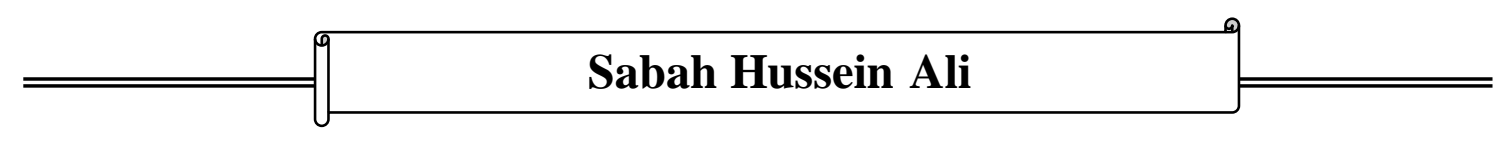

surface is perpendicular to the local plumb line. At the same time, the geoid is most graphical representation of the earth gravity field (ref.5).

The ellipsoidal height is reckoned, along the ellipsoidal normal, from the surface of any reference ellipsoid to the point of interest. The orthometric height is reckoned, along the curved plumbline, from the surface of the geoid to the point of interest. The geoid-ellipsoid separation (undulation) is reckoned, along the ellipsoidal to the normal, from the surface of any reference ellipsoid to the geoid (ref.6). Geoid undulation plays a major role in achieving the best possible accuracy when evaluating orthometric heights on the basis of GPS-derived ellipsoidal heights.

The objective of the present investigation is to measure the ellipsoid height by using Global Positioning System (GPS), and then estimate the orthometric height by using EMG96 global model of geoid undulation. The GPS-derived ellipsoidal heights of (19) points inside University of Mosul campus were performed with respect to the World Geodetic System 1984: WGS84 reference ellipsoid.

\section{Theoretical formulation}

The force acting on a body at rest on the earth's surface is the resultant of gravitational force and the centrifugal force of the earth's rotation. The total force, the resultant of gravitational force and centrifugal force, is called gravity (ref.7).

The potential of gravity, $w$, is the sum of the potentials of gravitational force (v) and centrifugal force $(\phi)$ as given in (ref.7) by the following equation:

$$
w=w(x, y, z)=v+\phi=k \iint_{v} \int \frac{\rho}{l} d v+\frac{1}{2} w^{2}\left(x^{2}+y^{2}\right)
$$

where;

$x, y, z$ is the rectangular coordinates system of the earth.

$k=-1$ in the determination of the geoidal undulation.

$\rho=$ mass density.

$l=$ spatial distance between two defined points with spherical coordinates.

The integration in equation (1) is extended over the earth. equation:

The gradient vector of $(w)$ is given as (ref.1) by the following $g=\operatorname{grad} w=\left(\frac{\partial w}{\partial x} i, \frac{\partial w}{\partial y} j, \frac{\partial w}{\partial z} k\right)$

which expresses the gravitational acceleration vector as gradient of $w$, the potential of gravity. The vector triad $\{I, j, k\}$ is the orthonormal set of the base vectors in space, pointing along the $x, y, z$ coordinate axes. 


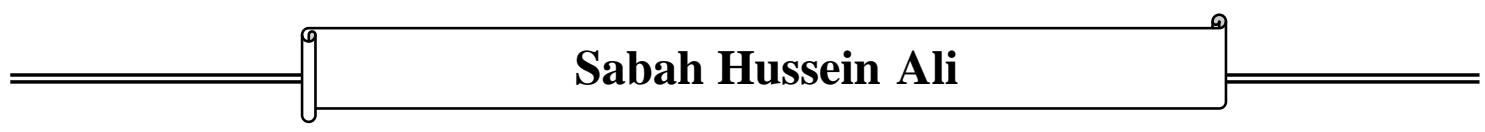

The magnitude of $(\mathrm{g})$ is called gravity, it has physical dimension of acceleration, the numerical value of ( $\mathrm{g}$ ) is a bout (978 gals) at the equator and (983 gals) at the poles.

When the potential $(w)$ is constant, i.e.; $w(x, y, z)=w_{o}=$ constant, the surface is called equipotential surfaces or level surfaces.

The line that intersect all equipotential surface normally are not exactly straight but slightly curved as shown in figure (1). They are called line of force, or plumb lines.

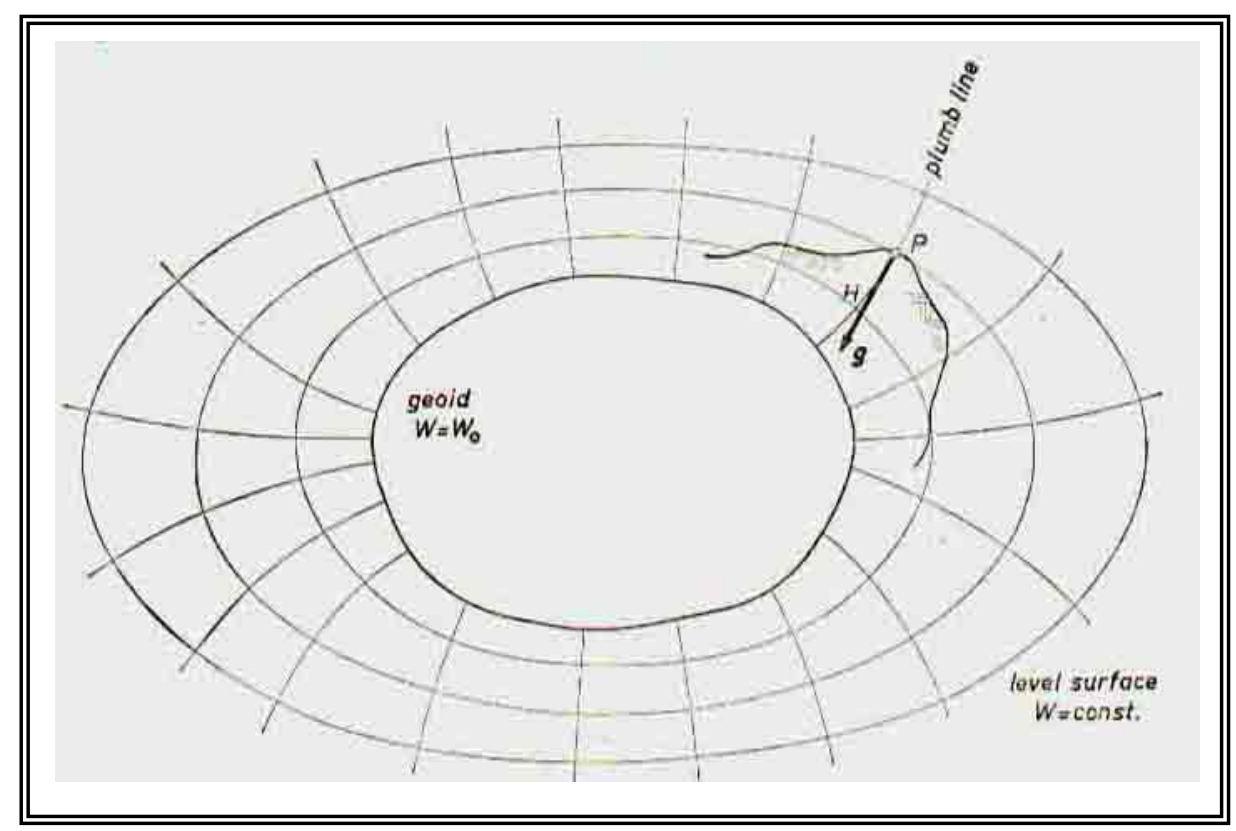

Figure (1): level surface and plumb lines (Ref.7)

The height $(\mathrm{H})$ of a point above sea level (also called, the orthometric height) is measured along the curved plumb line, starting from the geoid.

Geodetic measurements (theodolite measurements, leveling...etc) are almost exclusively referred to the system of level surfaces and plumb lines, the geoid playing an essential part.

From figure (2) the quantity (h) is the geometric height above the ellipsoid, it differs from the orthometric height $(\mathrm{H})$ above the geoid by the geoidal undulation $(\mathrm{N})$. 

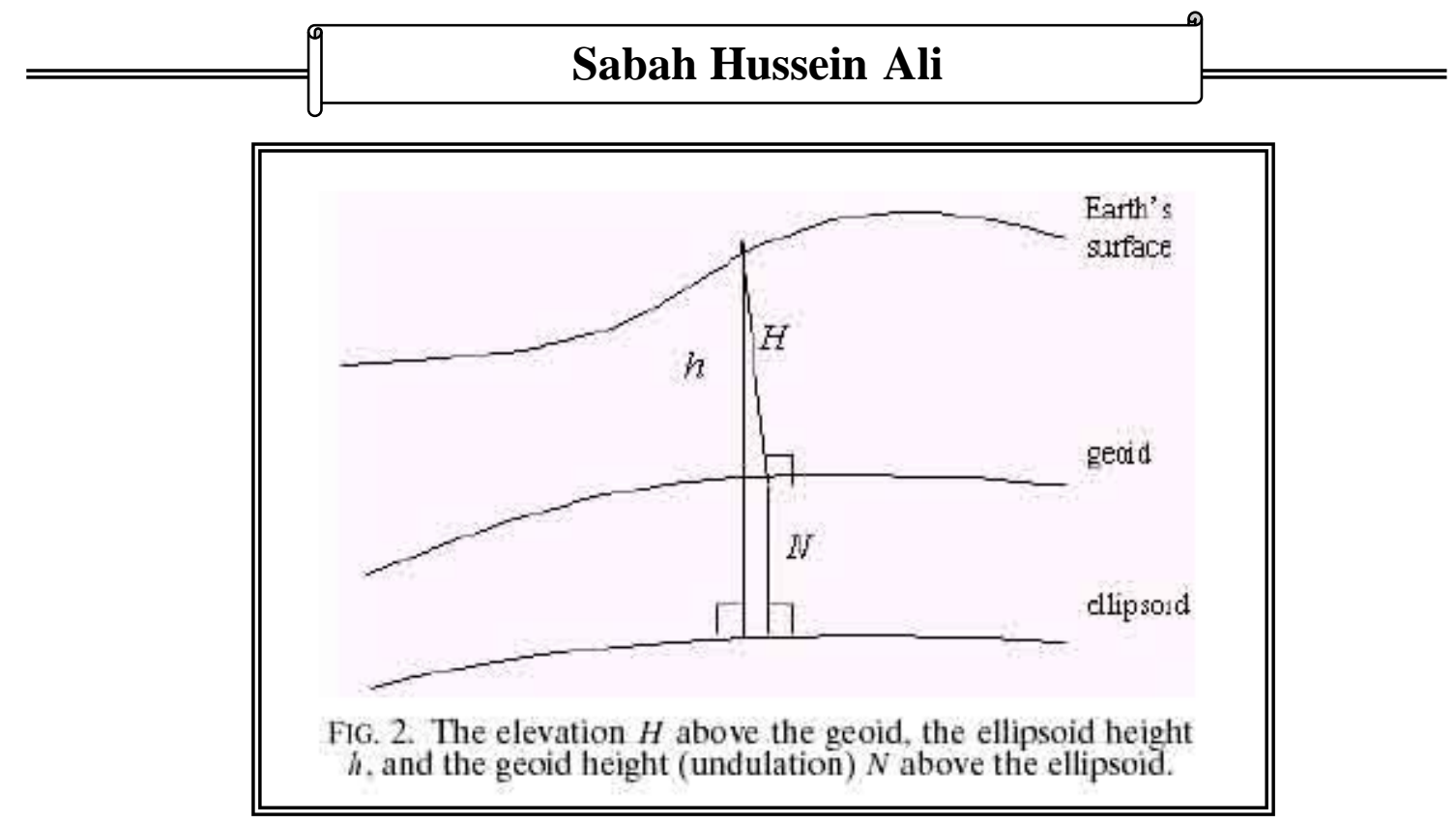

Figure (2): The elevation $(\mathrm{H})$ above the geoid, the ellipsoid height $(\mathrm{h})$, and the geoid height (undulation) (N) above the ellipsoid (3)

Then, the geoid undulation at any located points can be obtained by the resulting ellipsoidal height measured by Global Positioning System: GPS receiver and the observed orthometric height( approximately mean sea level) measured by leveling techniques, by the following relation (ref.3):

$$
\mathrm{h}=\mathrm{H}+\mathrm{N}
$$

where;

$$
\begin{aligned}
& \mathrm{h}=\text { ellipsoidal height } \\
& \mathrm{H}=\text { orthometric height } \\
& \mathrm{N}=\text { geoid height (undulation) }
\end{aligned}
$$

\section{GPS height measurements}

The technology of GPS uses a string of satellites that orbit some 20,000 kilometers $(12,500 \mathrm{mi})$ above the earth. Each satellite carries four atomic clocks so accurate that they might gain or lose an average of one second in 30,000 years (ref.8). As the satellites are orbit, they continuously transmit their simultaneous measurement of their positions, time signals, and other data. A GPS receiver records ( at the selected reference ellipsoid) the latitude, longitude, altitude (ellipsoid height), and the time.

In this study, A GARMIN GPS (Type: Etrex vista, Irland, LTD) was adopted for the heights and positions measurement. The average accuracy at each location measurement is $(4 \mathrm{~m})$ 


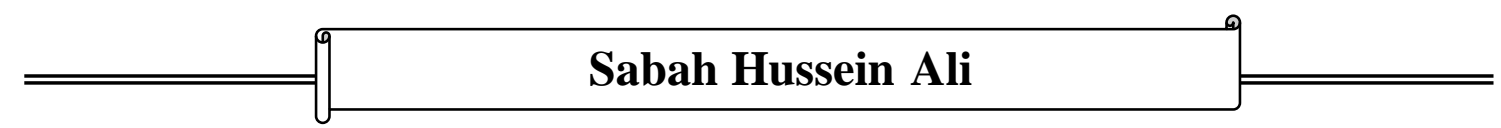

Figure (3) shows the satellite image of the study area as taken from earth google web site (ref.9).

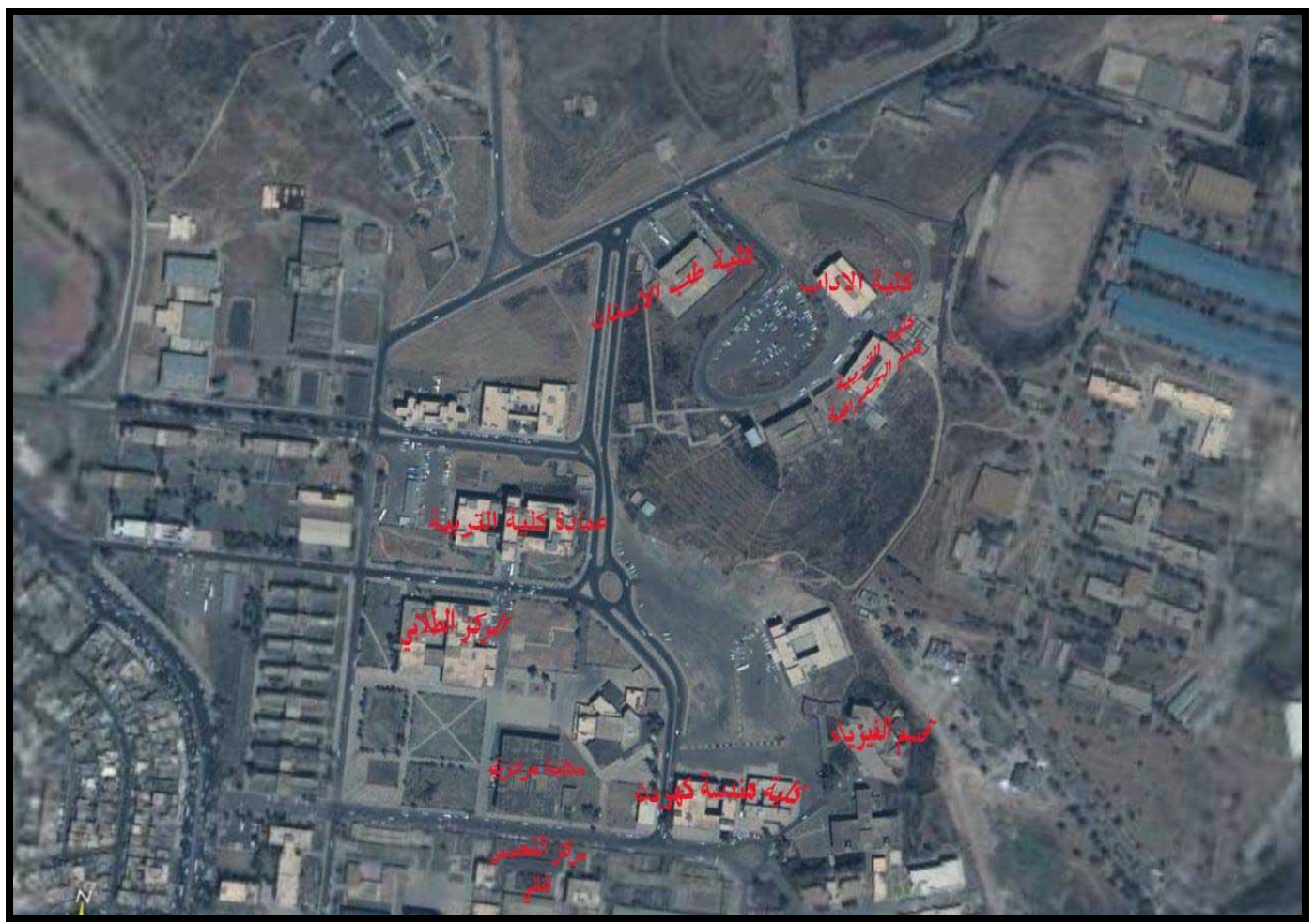

Figure (3): The study area inside Mosul University campus

\section{Earth Gravitational Model 1996 (EGM96)}

The Geoid is that equipotential surface of the Earth gravity field that most closely approximates the mean sea surface. At every point the geoid surface is perpendicular to the local plumb line. It is therefore a natural reference for heights - measured along the plumb line. At the same time, the geoid is the most graphical representation of the Earth gravity field

(ref.4).

The primary aim of the geodesy is to develop a geoid model, which is then used to connect the values of ellipsoid height, orthometric height, and geoid height (undulation).

The Earth Gravitational Model 1996 (EGM96) is one of the latest global geoid models that can be used to calculate the orthometric elevation when the values of ellipsoid heights are given by GPS positioning tool.

The EGM96 expressed by a spherical harmonic expansion of the gravitational potential and complete through degree and order 360 with an error range of \pm 0.5 to $\pm 1.0 \mathrm{~m}$ worldwide (ref.2). It is recommended to be used with the WGS84 ellipsoid (ref.3). Figure (4) shows the EGM96 map describing the global geoid undulation values with a range 


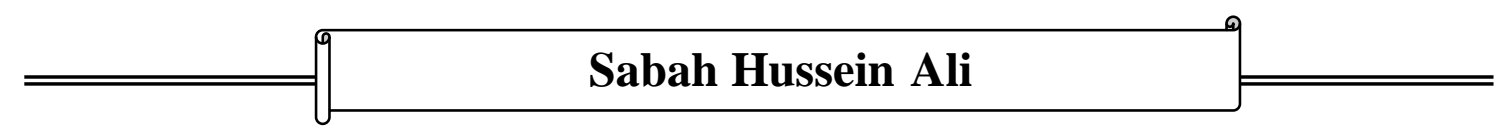

worldwide from $-105 \mathrm{~m}$ (located at the Indian Ocean) to $85 \mathrm{~m}$ relative to the WGS84 ellipsoid.

EGM96 is developed by National Imagery and Mapping Agency(NASA), National Imagery and Mapping Agency(NIMA), and the Ohio State University by using: (1) satellite tracking data from more than 20 satellites, including new data from GPS and TDRSS (Tracking and Data Relay Satellite System), as well as altimeter data from GEOSAT and ERS-1(Earth Resource Satellite) , (2) $30^{\prime} \times 30^{\prime}$ terrestrial gravity data from NIMA's comprehensive archives, (3) $30^{\prime} \times 30^{\prime}$ gravity anomalies derived from the GEOSAT Geodetic Mission altimeter data, as well as altimeter derived anomalies derived from ERS-1by KMS (Kort Matrikelstyrelsen, Denmark) in regions outside the GEOSAT coverage (ref.10, 11).

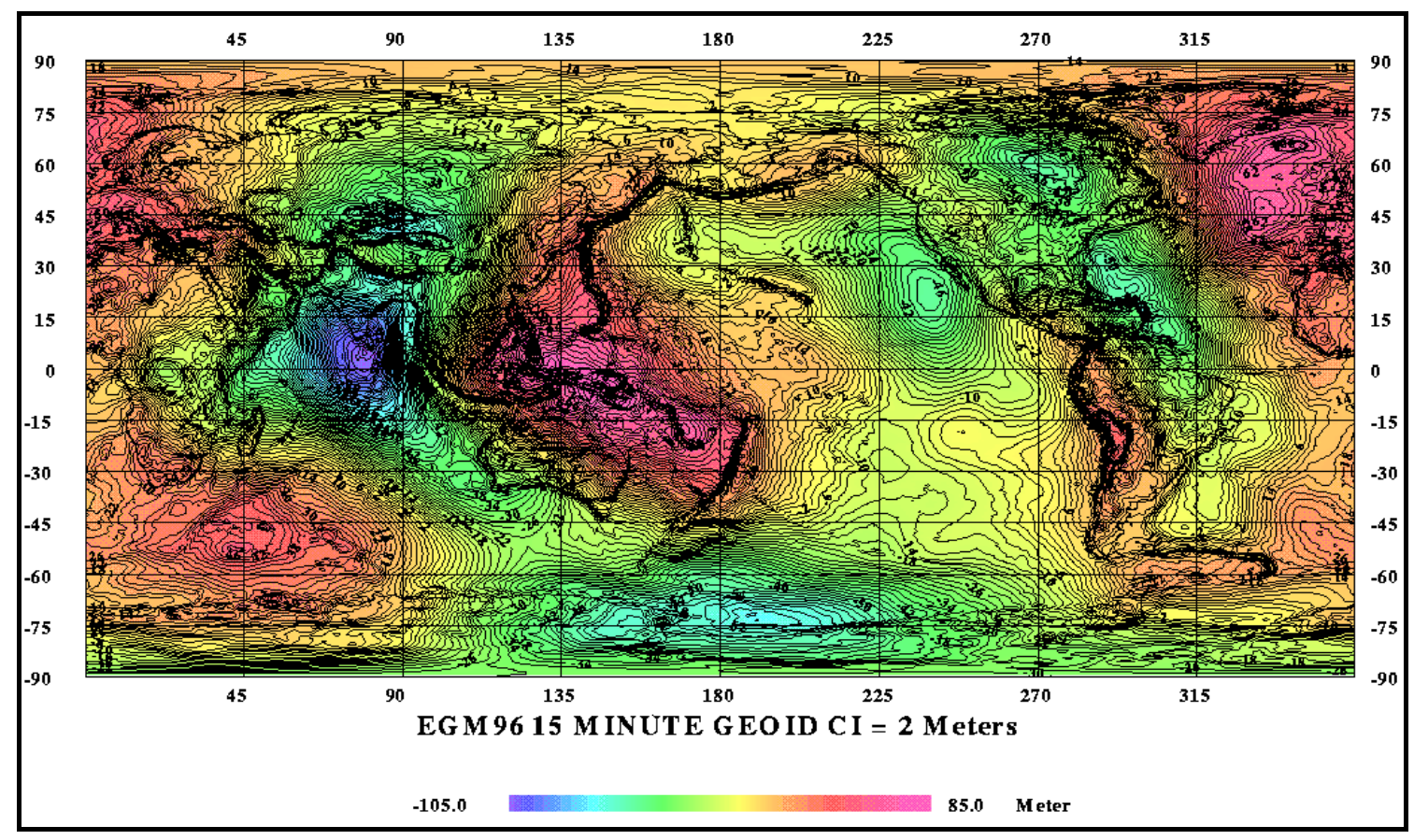

Figure (4): EGM96 global geoid undulation (ref.11)

\section{Results and Discussion}

The main task of this work was to calculate the orthometric heights (MSL) of selected locations distributed inside Mosul University campus according to the EGM96 global geoid. As shown in figure (5), test locations of (19) GPS geodetic control points inside Mosul University campus was used in this research. The study image and the related selected control points were projected and rectified by using ArcView3.3 software to be readout its coordinate system with respect to WGS84 reference ellipsoid. 


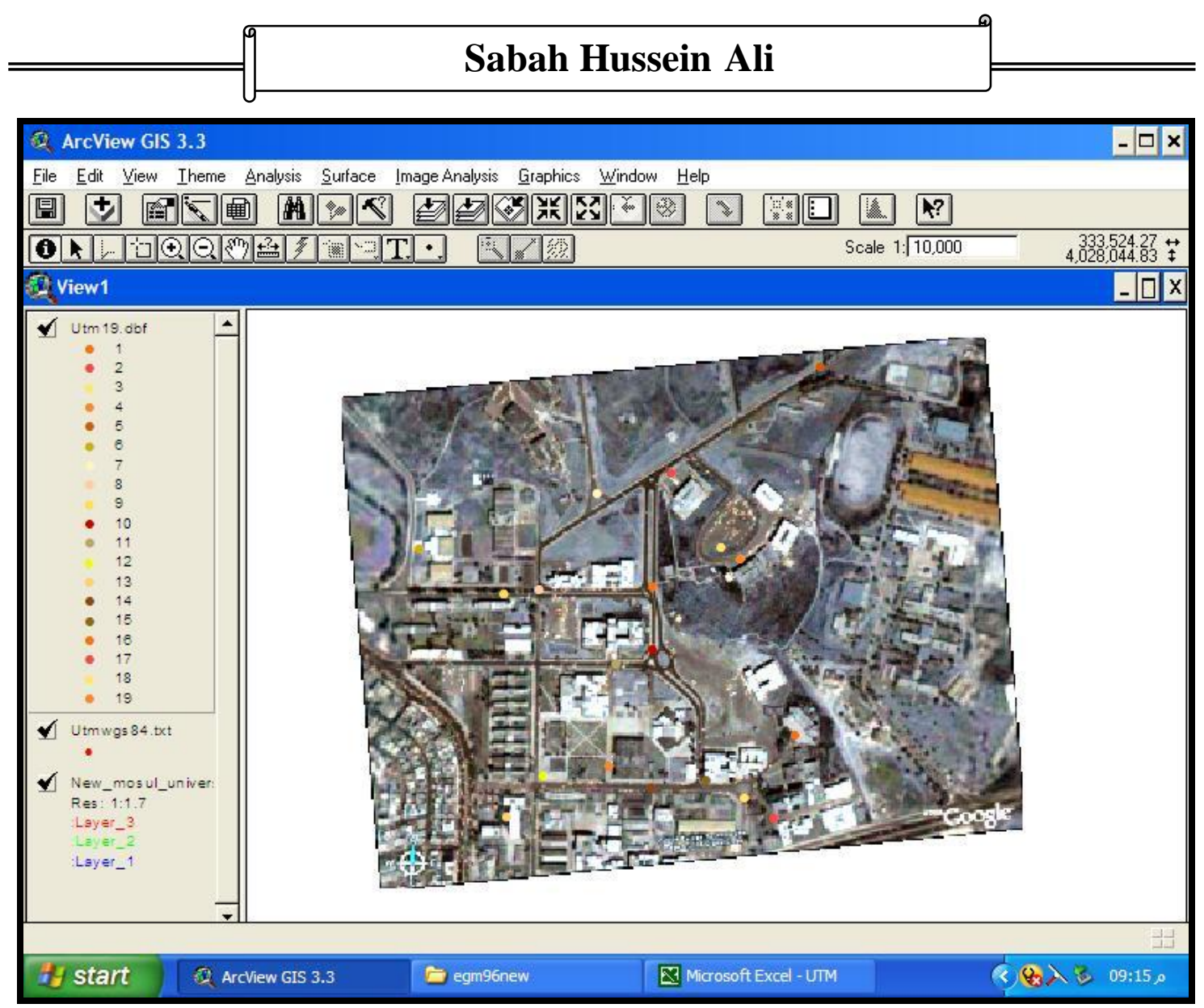

Figure (5): The geographical distributions of the GPS selected points inside Mosul university campus

The geoid height (undulation) $\mathrm{N}$, for the selected points was computed by using the EGM96 geoid correction calculator (ref.12). Then, the orthometric heights of the points were computed using their ellipsoidal heights and geoid heights (estimated on the basis of the EGM96 global geoid) from equation (3).

Table (1) summarizes the results of the ellipsoidal heights, geoid height, and the orthometric heights corresponding to the geographical coordinates of the selected locations. 
Table (1) : Results of (19) check points showing ellipsoidal heights (h), estimated geoid (N) and orthometric heights.

\begin{tabular}{|c|c|c|c|c|c|}
\hline $\begin{array}{c}\text { Point } \\
\text { No. }\end{array}$ & $\begin{array}{c}\text { Latitude } \\
(\mathrm{DMS})\end{array}$ & $\begin{array}{c}\text { Longitude } \\
(\mathrm{DMS})\end{array}$ & $\begin{array}{c}\text { Ellipsoidal } \\
\text { height }(\mathrm{h}) \\
(\mathrm{m})\end{array}$ & $\begin{array}{c}\text { Geoid } \\
\text { height(N) } \\
(\mathrm{m})\end{array}$ & $\begin{array}{c}\text { Orthometric } \\
\text { height }(\mathrm{H}) \\
(\mathrm{m})\end{array}$ \\
\hline 1 & $36: 22: 44.20$ & $43: 08: 44.30$ & 231 & 15.661 & 215.339 \\
\hline 2 & $36: 22: 50.90$ & $43: 08: 45.50$ & 224 & 15.674 & 208.326 \\
\hline 3 & $36: 22: 46.60$ & $43: 08: 49.20$ & 236 & 15.669 & 220.331 \\
\hline 4 & $36: 22: 45.90$ & $43: 08: 50.60$ & 241 & 15.668 & 225.332 \\
\hline 5 & $36: 22: 57.30$ & $43: 08: 56.20$ & 230 & 15.685 & 214.315 \\
\hline 6 & $36: 22: 46.10$ & $43: 08: 27.20$ & 218 & 15.663 & 202.337 \\
\hline 7 & $36: 22: 49.60$ & $43: 08: 40.10$ & 224 & 15.671 & 208.329 \\
\hline 8 & $36: 22: 43.90$ & $43: 08: 36.00$ & 219 & 15.665 & 203.335 \\
\hline 9 & $36: 22: 43.60$ & $43: 08: 33.40$ & 220 & 15.661 & 204.339 \\
\hline 10 & $36: 22: 40.50$ & $43: 08: 44.30$ & 222 & 15.660 & 206.340 \\
\hline 11 & $36: 22: 39.60$ & $43: 08: 41.80$ & 220 & 15.658 & 204.342 \\
\hline 12 & $36: 22: 32.90$ & $43: 08: 36.60$ & 216 & 15.648 & 200.352 \\
\hline 13 & $36: 22: 30.50$ & $43: 08: 34.00$ & 219 & 15.644 & 203.356 \\
\hline 14 & $36: 22: 32.30$ & $43: 08: 44.40$ & 221 & 15.659 & 205.341 \\
\hline 15 & $36: 22: 32.80$ & $43: 08: 48.50$ & 222 & 15.650 & 206.350 \\
\hline 16 & $36: 22: 35.60$ & $43: 08: 54.90$ & 225 & 15.656 & 209.344 \\
\hline 17 & $36: 22: 30.70$ & $43: 08: 53.40$ & 223 & 15.649 & 207.351 \\
\hline 18 & $36: 22: 31.80$ & $43: 08: 51.30$ & 221 & 15.650 & 205.350 \\
\hline 19 & $36: 22: 33.60$ & $43: 08: 41.30$ & 221 & 15.650 & 205.350 \\
\hline
\end{tabular}

*DMS= Degree:Minute:Second

Figure (6) shows the distribution of geoid undulation values (represented as different color surfaces) in Mosul University Campus according to the EGM96 global geoid model and the results in table (1). The figure also illustrates the distribution of the adopted control points inside the study area. The applied coordinate system in figure(6) is according to Universal Transverse Mercator: UTM with respect to WGS84. This coordinate system is very useful in determined the distance between any two points. Since the study area is very small as compared to the EGM96 global geoid calculations as shown in figure (4), the resulted geoid undulations were range from $15.644 \mathrm{~m}$ (minimum value) to $15.685 \mathrm{~m}$ (maximum value) as shown in the figure (6). This ranges values give an indicator that the Mosul University have been constructed on a mass distribution that have a geoid undulation of an average value of $15.6601 \mathrm{~m}$ which can be the correction factor to find the orthometric heights from the GPS data. 


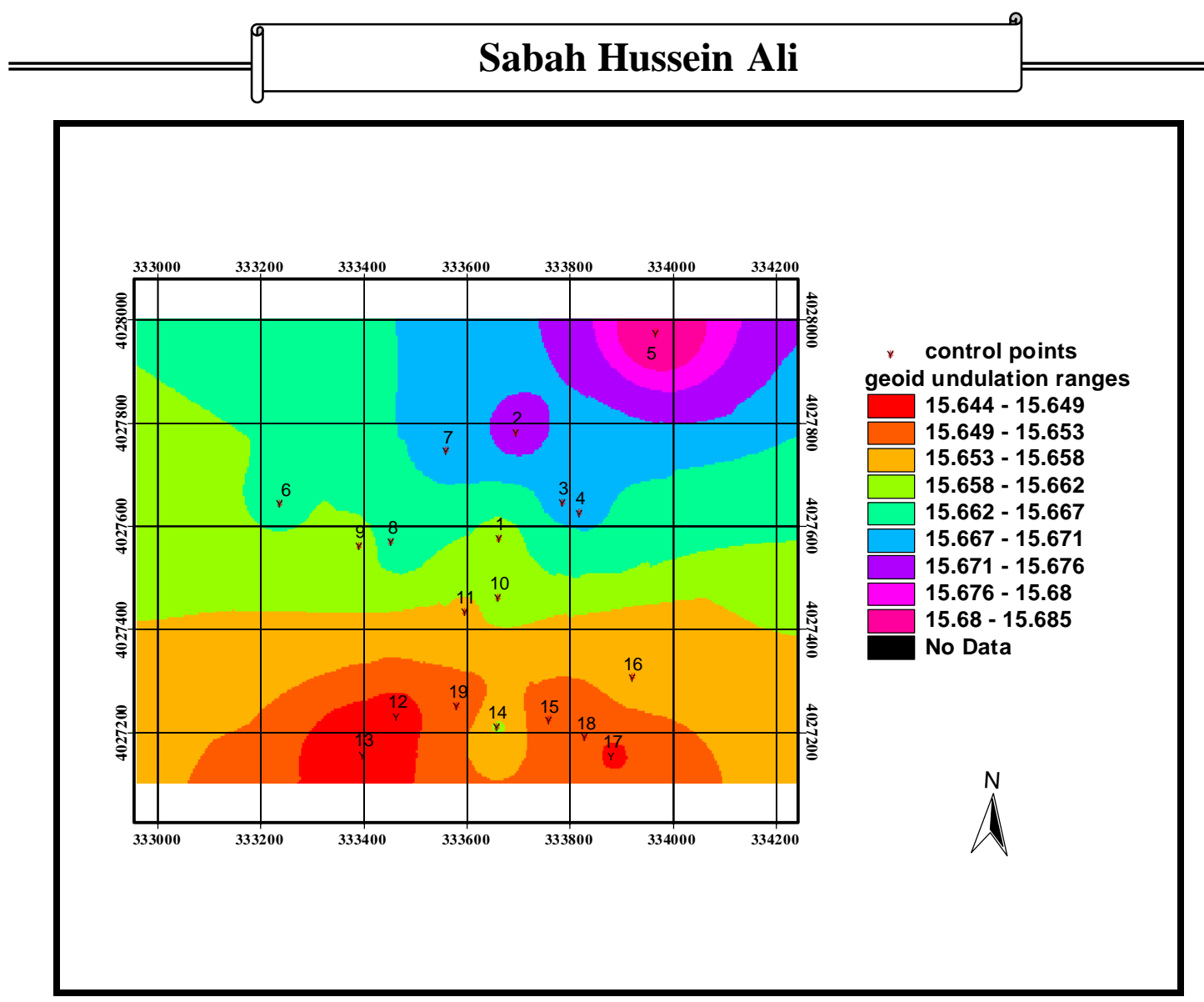

Figure (6): Map of Geoid undulation ranges inside Mosul University campus according to EGM96 global geoid model

One of the direct applications of modeling geoid undulation is computing orthometric height by the availability of GPS receivers. Figure (7) shows the contour map of the obtained values of orthometric heights derived from the obtained geoid undulation of the selected test points in the study area according to equation (1). As shown from the figure, the contour lines coincide very well with the different features in the base map. These good results come from the relatively high accuracy $(4 \mathrm{~m})$ of the adopted GPS receiver. Figure (7) illustrates that the area of height elevation was located at the points (4) $(225.332 \mathrm{~m})$, while the area of low elevation was located at the point (12) $(200.352 \mathrm{~m})$. Figure (8) shows a three- dimensional view of the obtained orthometric heights. 


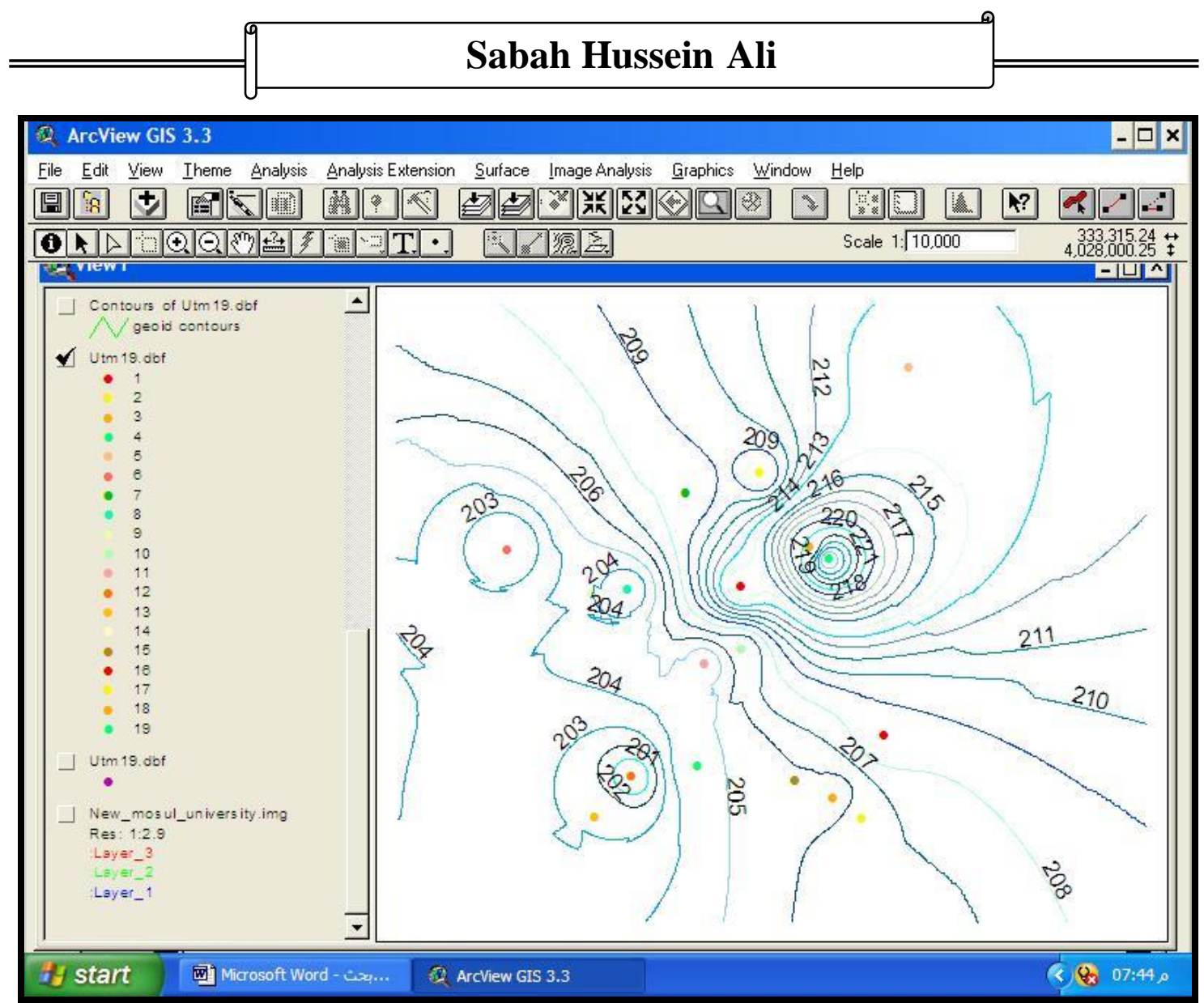

Figure (7): The orthometric heights contour map (1m intervals) of Mosul University

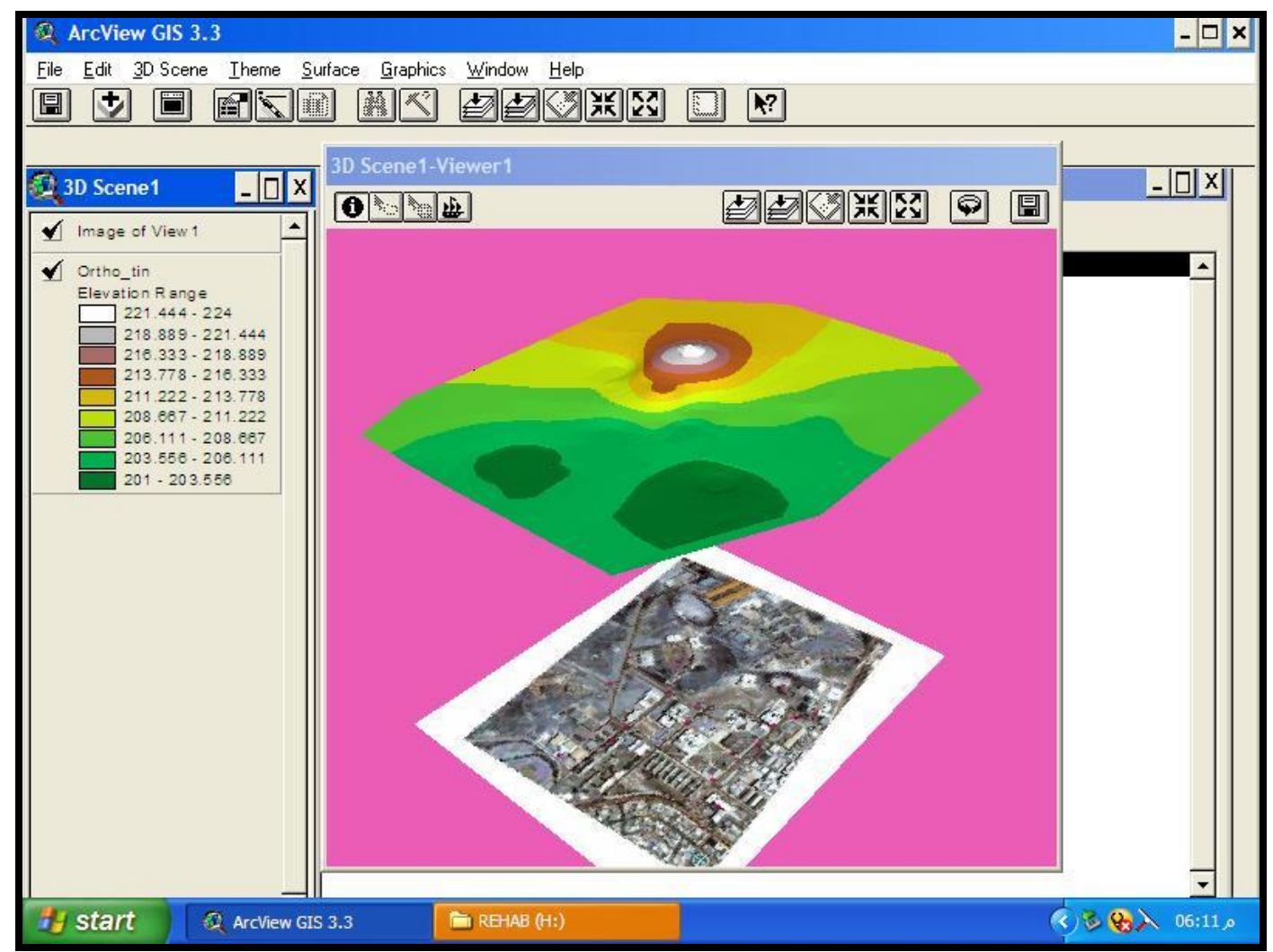

Figure (8): 3D view of the orthometric heights 


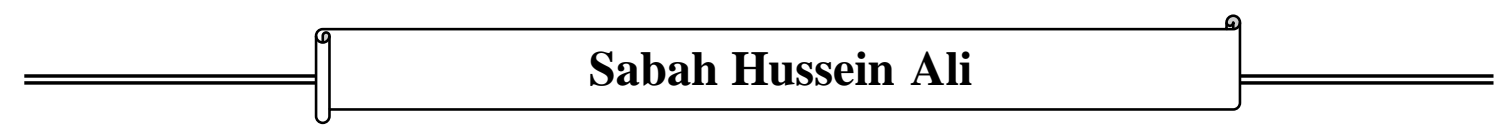

\section{Conclusions}

The results obtained in this study indicate that the chosen of EGM96 global geoid presented a good approximations for the geoid undulation and orthometric height of a small interested area inside Mosul University.

Based on the available data from the GPS receiver and EGM96 global geoid, the obtained average value of the geoid separation of the study area is $15.660 \mathrm{~m}$. This value can be used as a correction factor between GPS ellipsoidal height and the orthometric height.

Using the resulted geoid map, orthometric heights can be computed all over Mosul University, thus making the task of surveyors easier than in the past.

\section{References}

1. “ Physical geodesy", available at: http:// en.wikipedia .org/wiki/physical_geodesy", accessed at: $3^{\text {rd }} / \mathrm{May} / 2005$, pp.1-4.

2. Xiong, L., and Hans-Jurgen, G., 2001, "Tutorial: Ellipsoid, Geoid, Gravity, Geodesy, and geophysics", Geophysics, vol.66, no.6, pp.16601668 .

3. Joel, P., "Ellipsoids and The Geoid", available at: www.giscentrum.lu.se, accessed at :24 $4^{\text {th }} /$ April/2005.

4. "Earth's Geoid", available at: http://solid_earth.ou.edu/notes/geoid/earth's_geoid.html., accessed at: 13/june/2006, 16p.

5. "Datum Transformation Description", 2001, available at: www.laipac.com, accessed at: $2^{\text {nd }} / J a n u a r y / 2006$, pp.1-4

6. Featherstone, W. E., 2001, "Absolute and relative testing of gravimetric geoid models using Global Positioning System and orthometric height data", Computer and Geosciences, vol.27, pp.807-814.

7. Weikko, A. H., and Helmut, M.,1967, "Physical Geodesy", W. H. FREEMAN AND COMPANY, LONDON, pp.47-50.

8. Arthur, G., Judith, G., and Jerome, D., F., 1998, "Introduction to Geography", McGraw-Hill Companies, Inc., p.22.

9. "Earth Google", Release 4-BETA, available at: http://earth.google.com, accessed at 11/May/2006.

10.Lemoine, F.G., et al., 1996, " The Development of the NASA GSFC and NIMA Joint Geopotential Model", International Symposium on Gravity, Geoid, and Marine Geodesy, (GRAGEOMAR 1996), The University of Tokyo, Tokyo, Japan, September 30-October 5, 1996, 10p.

11."EGM96: The NASA GSFC and NIMA Joint Geopotential Model", NASA/TP-1998-206861, available at: http://cddisa.gsfc.nasa.gov/egm96.,accessed at : 7/june/2006.

12. " EGM96 geoid correction calculator", available at http://sps.unavco.org/geoid", accessed at: 19/june/2006. 